\title{
Microstructural Development and Tensile Strength of an ECAP - Deformed Al-4 wt. (\%) Cu Alloy
}

\author{
Érika Ferananda Prados, Vitor Luiz Sordi, Maurizio Ferrante* \\ Department of Materials Engineering, Federal University of São Carlos - UFSCar, \\ São Carlos - SP, Brazil
}

Received: March 3, 2008; Revised May 20, 2008

\begin{abstract}
The tensile strength of metals and alloys can be considerably increased by severe plastic deformation, a consequence of the extreme grain refinement thus achieved. In the present work the deformation was performed by Equal Channel Angular Pressing and the material was an $\mathrm{Al}-4 \% \mathrm{Cu}$ alloy. Characterization included tensile tests, and microstructural observation by optical and transmission electron microscopy. After four passes, the yield strength showed an increase of $310 \%$ over the undeformed alloy, a figure reduced to $160 \%$ by a $250{ }^{\circ} \mathrm{C}$ / 1 hour post - deformation anneal. Additionally, the alloy displayed a very low work hardening capacity, especially after the annealing heat treatment. After four deformation passes the grain size of the annealed specimens was estimated to be close to $500 \mathrm{~nm}$. The tensile behaviour and the absence of work hardening were discussed in terms of the fine microstructure.
\end{abstract}

Keywords: $E C A P, A l-4 \% C u, S P D$, tensile properties, microstructure, work-hardening

\section{Introduction}

In the last ten years a large number of investigations regarding a severe plastic deformation (SPD) technique called Equal Channel Angular Pressing (ECAP), were published in the wake of the pioneering work by Valiev et al. ${ }^{1}$ and $\mathrm{Segal}^{2}$. Justification for this interest lies in the fact that ECAP- deformed metals and alloys exhibit a very small grain size and consequently, their tensile strength is remarkably improved. All relevant work on this SPD technique has been recently summarized by Valiev and Langdon in a comprehensive review ${ }^{3}$. The microstructural evolution of metals and alloys subjected to low and medium plastic deformation has been discussed by Liu and Hansen ${ }^{4}$, and Bay et al. ${ }^{5}$. The outcome of these studies is a model describing how, in severely deformed metals with high to moderate stacking fault energy, grain subdivision takes place by the formation of cell blocks separated by arrays of geometrically necessary dislocations. Within these cells there are regions relatively free from dislocations, bounded by low angle boundaries. The more severe the deformation, the narrow the cell blocks become, until the cell boundaries transform into high angle boundaries. This sequence has been often observed in ECAP deformed metals and alloys and seems to explain the formation of very small grains ${ }^{6,7}$. A still active dispute is how the high angle dislocation boundaries transform into grain boundaries; on this respect, a study by Chang et al. ${ }^{8}$ identified three types of boundaries in commercially pure Al subjected to ECA - deformation: i) polygonized dislocation walls of the type described by Bay et al. ${ }^{5}$; ii) partially transformed boundaries, and iii) proper grain boundaries. The evolution of type i to type iii takes place by the dissociation of lattice dislocations and their absorption into the boundaries. This process decreases the free energy of the system since the resulting grain boundaries are of the equilibrium type.

As for the tensile behaviour, strength enhancement is a consequence of the very small grain size, and as such the Hall-Petch relationship still applies, since for ECAP- deformed materials the grain size does not go below $\approx 200 \mathrm{~nm}$ and said relationship only breaks down for grains smaller than $\approx 25 \mathrm{~nm}^{9}$. Of course, in SDP materials, dislocation hardening must contribute to the total strength, but the relative proportion is unknown; at any rate, grain size hardening is the dominant mechanism. Although ductility loss appears to be a customary occurrence, improvement of that property was observed in some cases and attributed to the non-equilibrium state of the grain boundaries, which allows mechanisms such as boundary sliding and grain rotation ${ }^{10}$. However, direct evidence of these mechanisms is still lacking.

This work reports on a number of observations performed on an Al-4wt $\% \mathrm{Cu}$ alloy containing a coarse dispersion of $\mathrm{Al}_{2} \mathrm{Cu}$ particles. Deformation was carried out by ECAP in a $\Phi=120^{\circ}$ die. Tensile behaviour and microstructural evolution were characterized and discussed, keeping in view the current theories on both substructure formation and the enhancement of tensile properties by SPD.

\section{Experimental}

\subsection{Material}

$\mathrm{An} \mathrm{Al}-\mathrm{Cu}$ alloy was prepared in an induction furnace by melting commercially pure $\mathrm{Al}$ and electrolytic $\mathrm{Cu}$. Chemical composition was $\mathrm{Al}-4.1 \% \mathrm{Cu}-0.067 \% \mathrm{Fe}$ and the alloy was poured into a steel mould from which prismatic samples with dimensions $14 \times 14 \times 75 \mathrm{~mm}^{3}$ were machined out and subsequently homogenized at $530{ }^{\circ} \mathrm{C} /$ 24 hours. This was followed by furnace cooling so as to obtain large $\mathrm{Al}_{2} \mathrm{Cu}$ precipitates.

\subsection{ECA deformation}

A die with $\Phi=120^{\circ}$ and $\psi=0^{\circ}$ (inner and outer radii of curvature equal to $8 \mathrm{~mm}$ ) was employed. The control sample was identified as $0 \mathrm{X}$ and the deformed samples as $1 \mathrm{X}, 2 \mathrm{X}, \ldots$ etc. with the numeral indicating the number of passes. Pressing was carried out in a $25 \mathrm{t}$ INSTRON model $5500 \mathrm{R}$ operating at $5 \mathrm{~mm}$ per minute. Route A was employed, meaning that the sample is pressed without rotation between passes, the lubricant was a $\mathrm{Mo}_{2} \mathrm{~S}$ paste and a maximum of five passes was applied. Figure 1 shows the die, its geometrical 

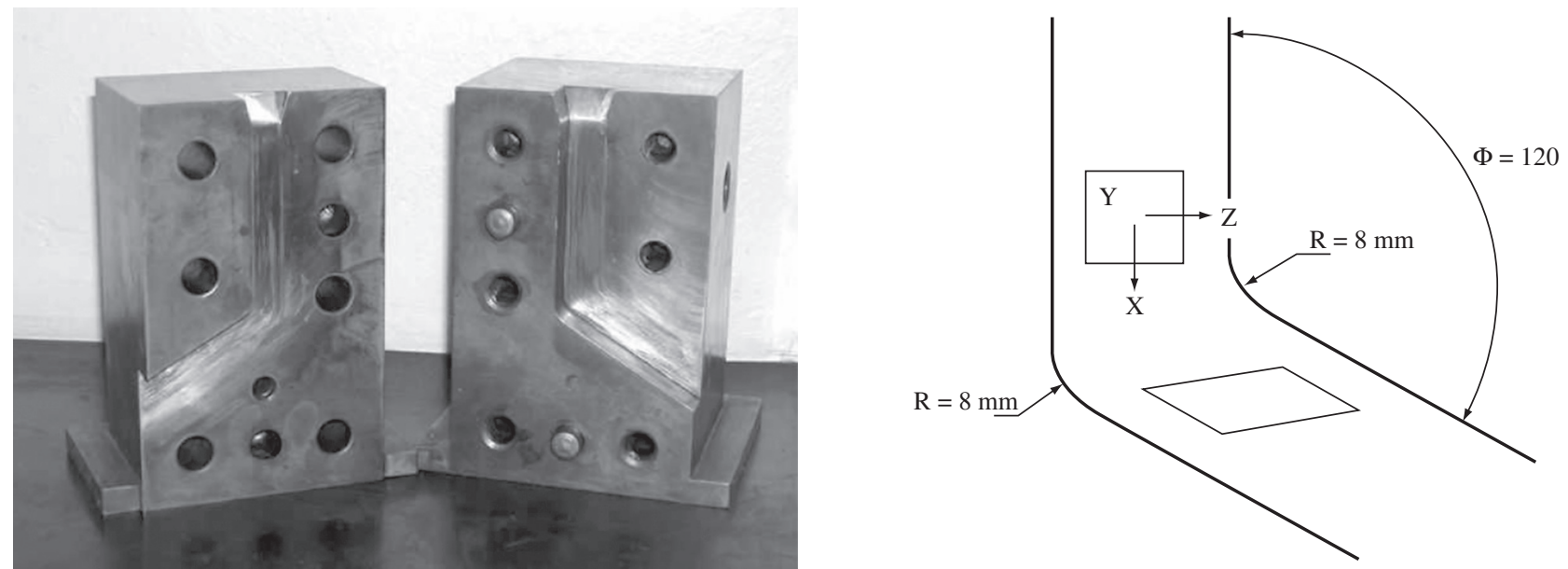

Figure 1. Photograph of the ECAP die and schematic of the geometry of the die channel, plus sample planes identification.

parameters, the $\mathrm{X}, \mathrm{Y}$ and $\mathrm{Z}$ planes of the sample and their orientation with respect to the die.

\subsection{Post-deformation heat treatment}

The deformed samples were annealed at $250{ }^{\circ} \mathrm{C} / 1$ hour, thus forming the XR series of samples: 0XR, 1XR, 2XR... etc. Some samples were annealed at $300{ }^{\circ} \mathrm{C} / 1$ hour.

\subsection{Characterization}

Tensile tests were employed to determine maximum tensile stress, yield stress, elongation, strain hardening exponent and deformation energy to fracture, also known as static toughness. Calculation of the strain hardening exponent followed the procedure given by ASTM E $646-00^{\dagger}$ whilst static toughness was given by the total area under the engineering stress - strain curve. Flat tensile specimens were machined out from the ECAP deformed samples by spark erosion; dimensions were $3 \times 2 \mathrm{~mm}^{2}$ and $13 \mathrm{~mm}$ gauge length. Transmission electron microscopy (TEM) was employed to follow the microstructural development of the deformed and post - deformed annealed samples, as a function of pass number. Thin foils observation was carried out in a Phillips ${ }^{\circledR}$ CM 120 electron microscope; specimens were prepared by polishing $3 \mathrm{~mm}$ diameter discs until perforation in a TENUPOL3 equipment and the electrolytic solution consisted of methanol / nitric acid in the proportion of 7 to 3. Operating conditions were $15-20 \mathrm{~V}$ and $-30{ }^{\circ} \mathrm{C}$. Conventional light microscopy completed the microstructural characterization.

\section{Results}

\subsection{Tensile properties}

Figure $2 \mathrm{a}$ shows the engineering stress strain curves of undeformed and ECAP - deformed specimens, the latter group tested in the as-deformed condition and after annealing. It can be seen that both strength and elongation increase with the number of passes; the graph in Figure $2 b$ gives a more precise description of the tensile behaviour, which can be summarized as follows: i) maximum strength is attained after four passes; ii) elongation increases with respect to the undeformed sample, but there is a sharp ductility drop after the first pass; however, elongation gradually recovers reaching a maximum after pass number four; iii) yield strength and ductility increase slowly

$\dagger$ Standard Test Method for Tensile Strain-Hardening Exponents ( $n$-Values) of Metallic Sheet Materials: plastic true strain and true stress were fitted to the Hollomon expression $\sigma=\mathrm{k} \varepsilon^{\mathrm{n}}$.
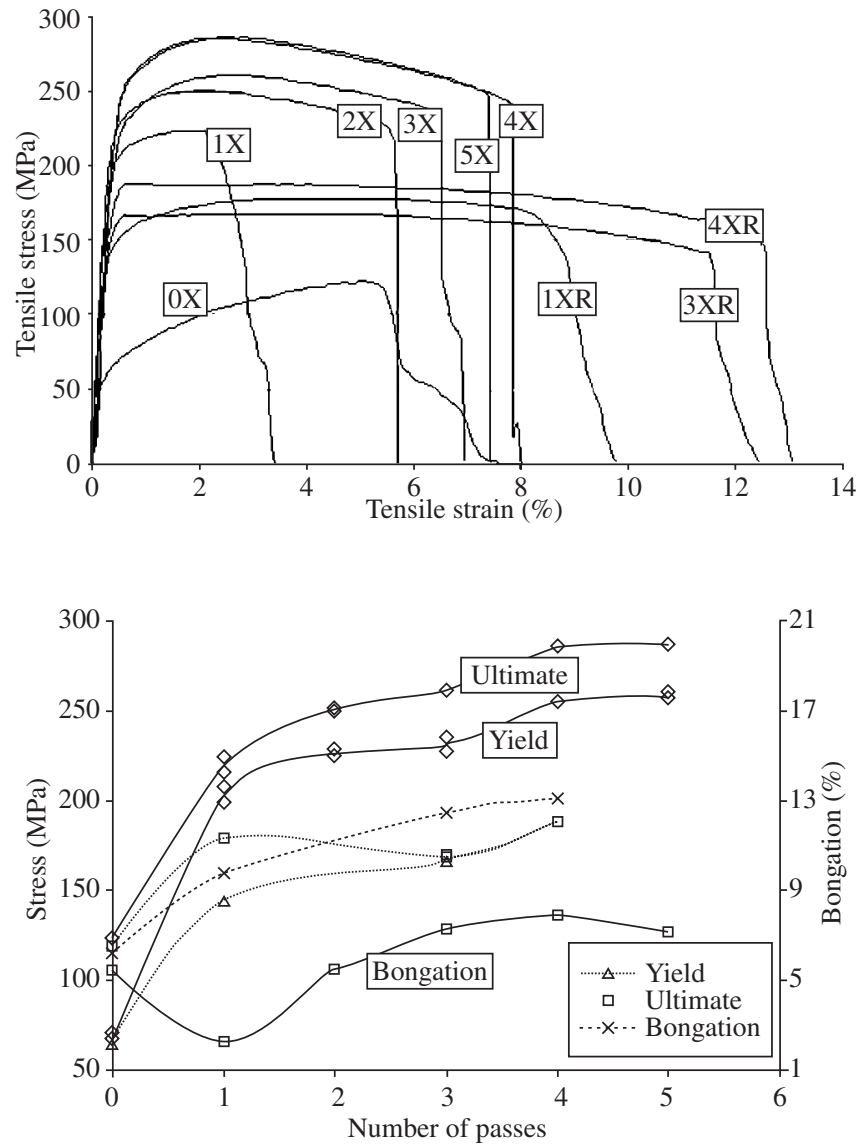

Continous lines: $525^{\circ} \mathrm{C}(24$ hours $)$ - ECAP - Tensile test

Dot lines: $525^{\circ} \mathrm{C}$ ( 24 hours) - ECAP - $250^{\circ} \mathrm{C}$ (1 hour) - Tensile test

Figure 2. Tensile data of the $\mathrm{Al}-4 \% \mathrm{Cu}$ alloy in the undeformed, ECA - deformed and post-deformation annealed conditions: a) engineering stress-strain curves; b) test parameters, that is, yield, ultimate strength and elongation.

up to $310 \%$ and $33 \%$ with respect to the undeformed sample; and iv) annealing at $250{ }^{\circ} \mathrm{C}$ causes $\mathrm{a} \approx 20 \%$ decrease of yield strength (for $4 \mathrm{XR})$, combined with a substantial ductility improvement $(+63 \%)$ over the $4 \mathrm{X}$ specimen. Finally, the work-hardening effect was very low, particularly for the annealed samples. 
More detail on the work hardening behaviour is given in Figure 3, where the parameters of the Hollomon equation, $\sigma=\mathrm{k} \varepsilon^{\mathrm{n}}$, are plotted as a function of the number of passes. These results show that the exponent $\mathbf{n}$ decreases continuously with deformation up to approximately one fifth of the original value (0X sample), whilst $\mathrm{k}$ scales with the maximum strength.

Finally, the static toughness was calculated as a function of the imposed shear strain, calculated by the Iwahashi formula ${ }^{11}$. Figure 4 shows the data and includes results obtained by Fang and co-workers on an $\mathrm{Al}-3.9 \% \mathrm{Cu}$ alloy ${ }^{12}$; it can be seen that the deformation energy values obtained in the present investigation are consistently higher.

\subsection{Microstructure}

Figure 5 shows optical micrographs illustrating the microstructural evolution of the Al-4\% Cu alloy with ECAP - deformation. Main features are: i) severe grain elongation, and macroscopic shear patterns with angular ranges slightly different from those theoretically predicted by Furukawa, Horita and Langdon ${ }^{13}$, see Figures 5a,b,e; ii) fracture of the large precipitates formed during slow cooling, a phenomenon better imaged in Figure 5c; and iii) internal fragmenta-

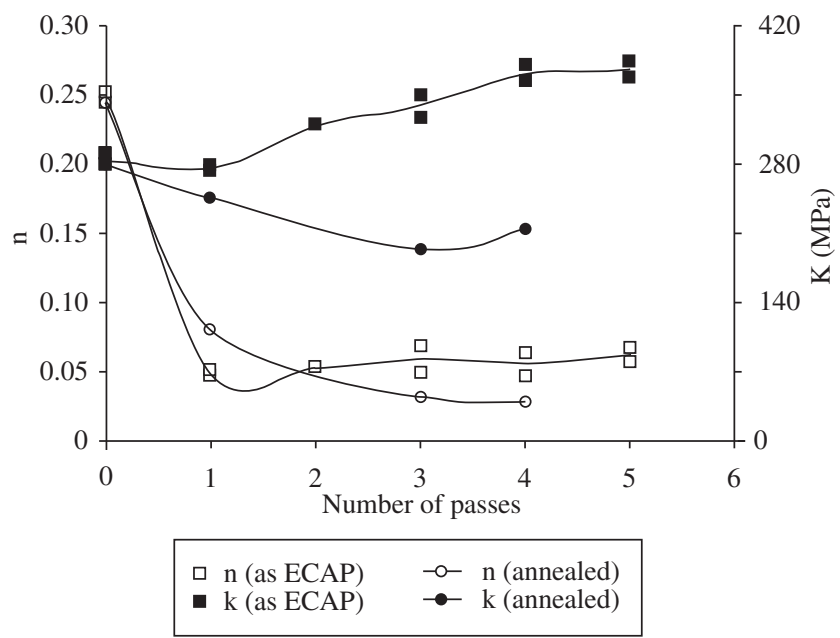

Figure 3. Evolution of the parameters of the Hollomon equation with the number of ECAP passes.

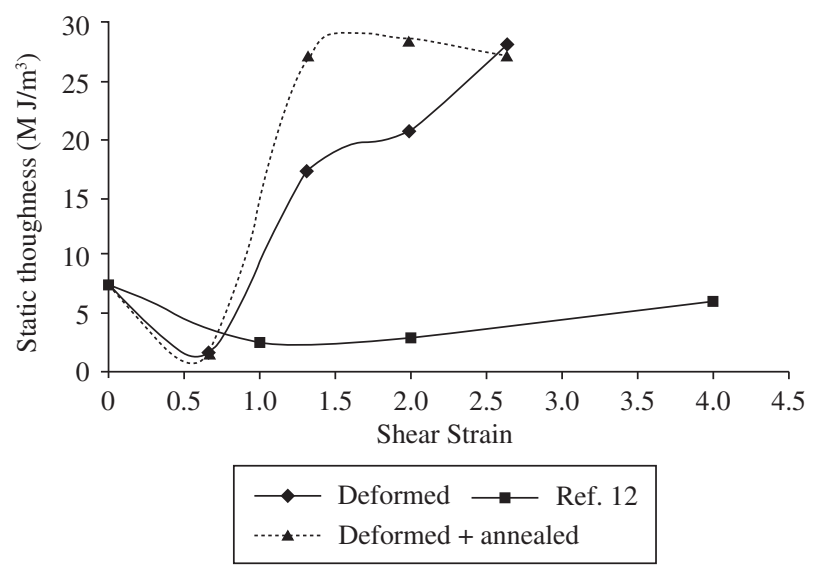

Figure 4. Evolution of the static toughness as a function of shear strain.

tion of the elongated grains, making an angle of approximately $60^{\circ}$ with the pressing direction see Figure $5 \mathrm{~d}$.

The fine microstructure is revealed by TEM, see examples in Figure 6 . The corresponding diffraction patterns show that the $1 \mathrm{X}$ specimen contains a high proportion of low angle boundaries, see streaked diffraction spots, whilst further deformation increases grain misorientation, as revealed by the ringed diffraction pattern produced by the $4 X$ sample.

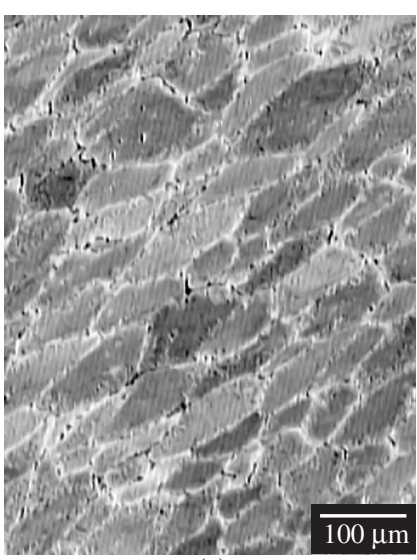

(a)

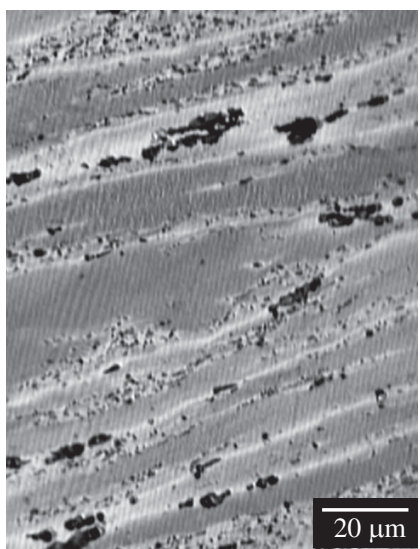

(c)

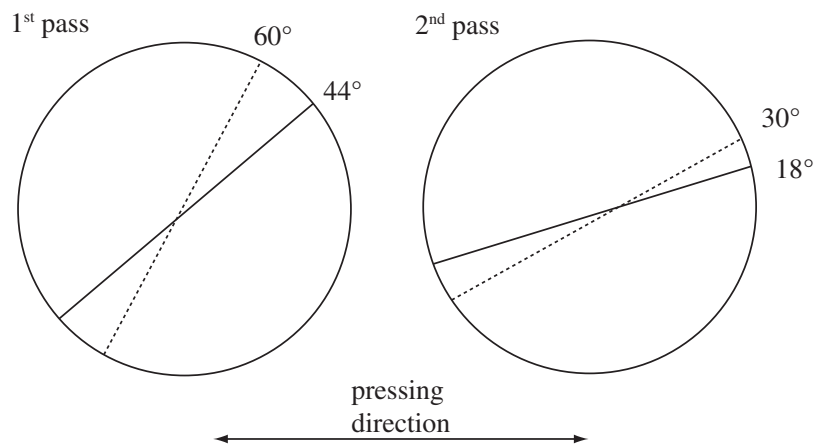

(e)

Figure 5. Optical micrographs of the ECAP-pressed samples taken on plane Y: a) after one pass; b) after two passes; c) higher magnification of the $2 \mathrm{X}$ sample, showing alignment and fracturing of the $\mathrm{Al}_{2} \mathrm{Cu}$ particles; d) example of grain internal fragmentation in a $2 \mathrm{X}$ specimen; e) theoretical (dotted lines) and observed (solid lines) angular ranges of the slip traces on plane Y. 


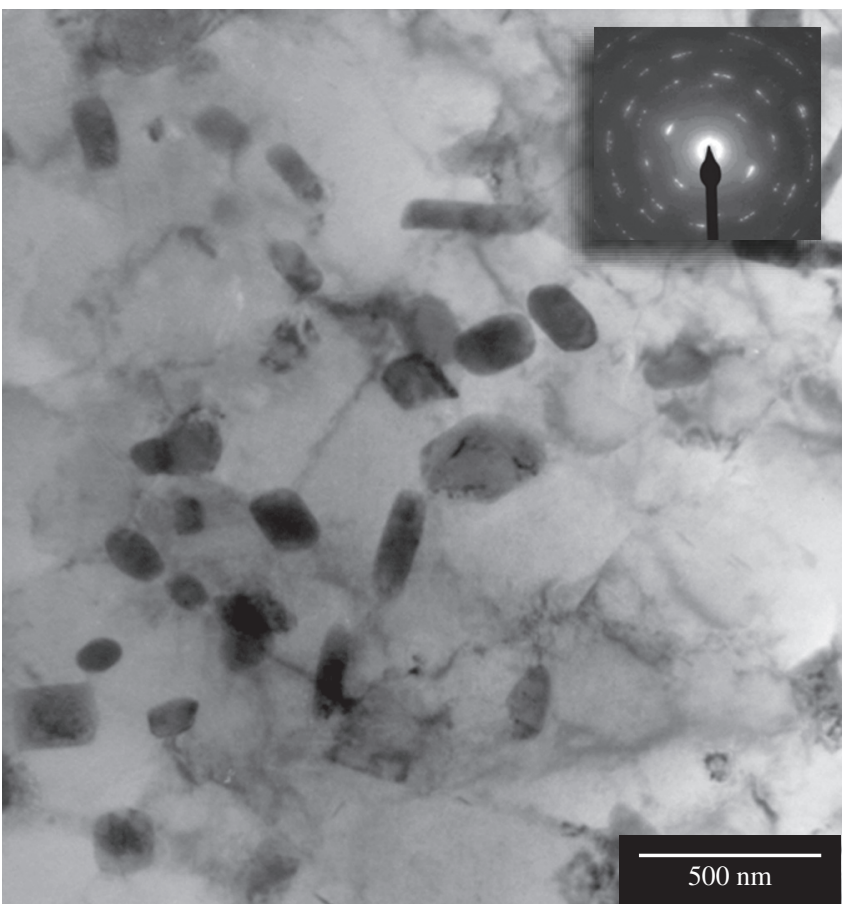

(a)

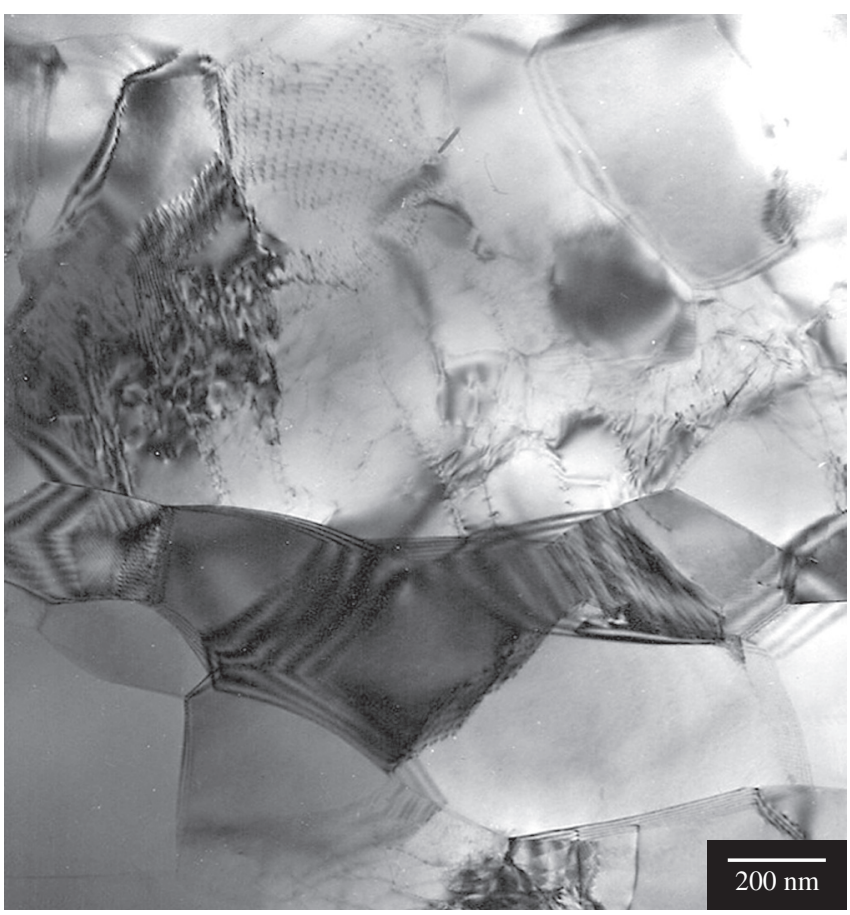

(c)

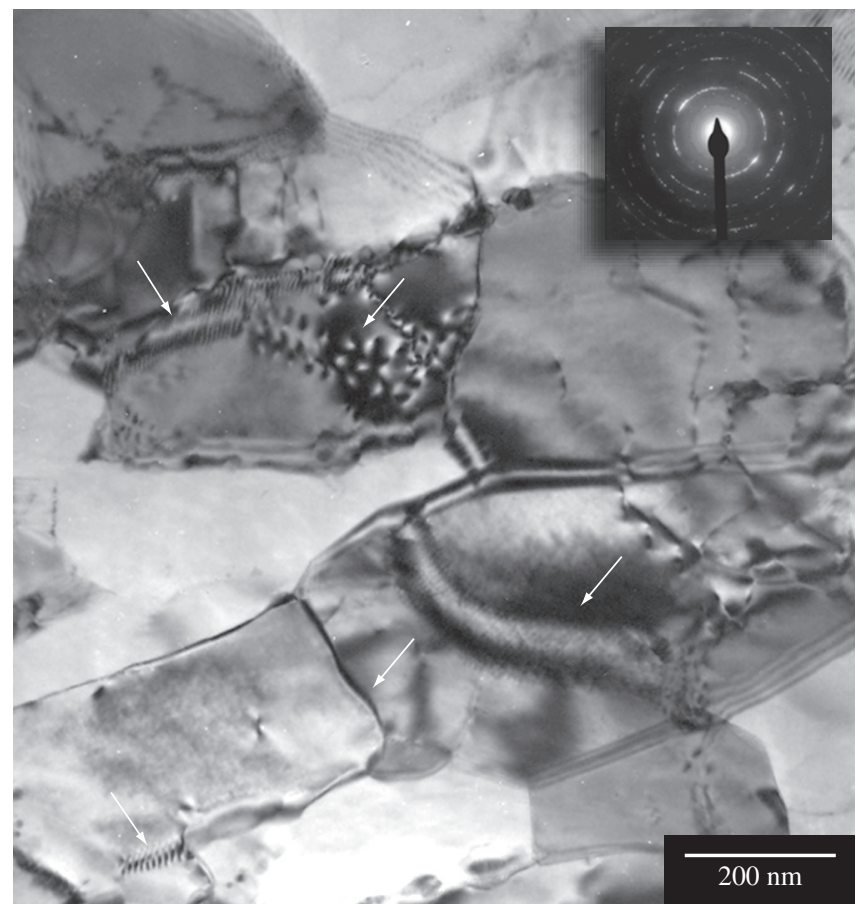

(b)

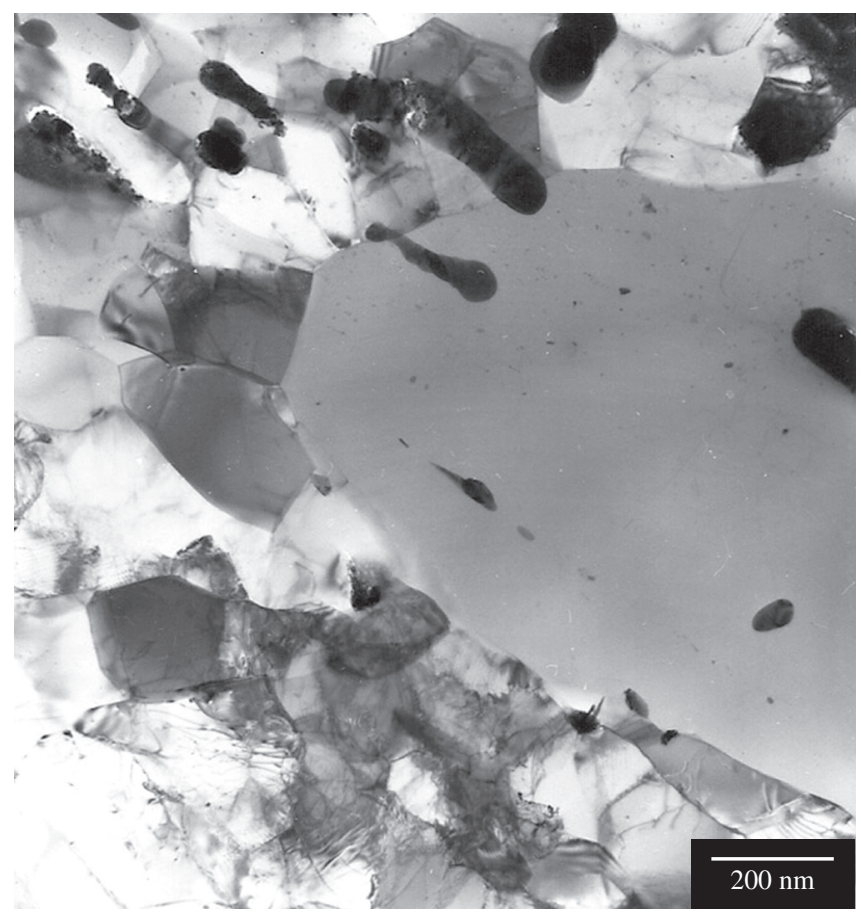

(d)

Figure 6. TEM micrographs of deformed samples: a) $1 \mathrm{X}$ specimen; b) $4 \mathrm{X}$ specimen; c and d) samples $4 \mathrm{XR}$, annealed at $250{ }^{\circ} \mathrm{C}$ and $300{ }^{\circ} \mathrm{C}$, respectively.

\section{Discussion}

Although most investigations employed dies with channels making $90^{\circ}$, a different solution, that is, $\Phi=120^{\circ}$, was quite satisfactory despite a lower strain per pass, see Iwahashi formula ${ }^{11}$. Indeed, the association of this angle with Route A, which is the practice employed in the present set of experiments, was identified as the optimal procedure for $\mathrm{Al}$ alloys ${ }^{14,15}$.

\subsection{Tensile properties}

The considerable increase of tensile strength shown in Figure 2 is a characteristic of severely deformed metals and alloys. However, in most reported cases the ductility decreases, but surprisingly the present results show the opposite trend. To understand this result it must be pointed out that the ductility of the reference sample (OX) was relatively low. From this, plus detailed observation of the fracture 
morphology of the tensile specimens, a different picture emerges. Indeed, from Figure 2, it can be seen that the elongation of the reference sample is equal to $6.2 \%$, a very low figure; in comparison, a separate experiment in which an identical alloy was conventionally extruded and tested in tension showed elongation equal to $19 \%$. Figure 7 is a scanning electron micrograph of the $0 \mathrm{X}$ sample fracture surface ${ }^{16}$; solidification voids are clearly seen, and a void-dominated fracture path is consistent with the wavy stress - strain curve of this sample, see Figure 2, which also shows that fracture takes place with no area reduction. In conclusion, the ductility improvement here observed is an artifact due to the low initial ductility of the cast alloy. However, the solidification defects seems to have been progressively healed by the ensuing passes and this is consistent with the observed ductility enhancement observed from the second pass on.

Another important feature of the tensile behaviour here observed is the absence of work hardening. This is a common occurrence in ECA-deformed material, consistently attributed to the low density of mobile dislocations due to mutual annihilation and absorption by the grain boundaries. These mechanisms are made easy in nano and sub-microcrystalline materials by the small diffusion distances ${ }^{17}$, or by dynamic recovery ${ }^{18}$. The latter phenomenon is likely to occur in $\mathrm{Al}$ since room temperature corresponds to approximately $0.3 \mathrm{~T}_{\mathrm{m}}$ (homologous temperature). A practical consequence of the lack of work hardening is unstable deformation leading to fast necking and specimen fracture. However, Figure 2 shows that a very large fraction of the total elongation takes place after the onset of necking, in other words, from the point of maximum stress, up to the fracture strain. For instance, taking the $4 \mathrm{X}$ sample, it can be seen that more than $70 \%$ of the total deformation occurs in the non-homogeneous deformation regime, in other words, necking is a very slow process. Furthermore, after the annealing heat treatment that regime occupies almost the total strain undergone by the sample. This behavior is an indication of superplasticity, which is one among the benefits of the ECAP technique ${ }^{19}$, but of course, its full achievement requires a combination of strain rates and testing temperatures which are outside the scope of the present paper. Finally, Figure 3 clearly indicates that the work hardening capacity is further decreased by the $250^{\circ} \mathrm{C}$ post deformation heat treatment. The explanation resides in the difference of intragranular dislocation density, which is lower in the annealed samples, and in other fine microstructure features, such as grain (or sub-grain) size and the nature of the internal boundaries.

As for the influence of the deformation level on work hardening, more information is gathered from Figure 8, an enlargement of the engineering stress - strain curves of the annealed ECAP samples. It is apparent that the extent of work hardening of the $1 \mathrm{XR}$ and $4 \mathrm{XR}$ samples is different, and possible causes are differences on the dislocation density and their annihilation rate. These tentative statements will be justified when discussing the fine microstructure.

\subsection{Microstructure}

The optical micrographs show grain elongation and slip traces making an angle of $45^{\circ}$ (first pass) with respect to the extrusion direction and $18^{\circ}$ (second pass), see Figures 5a,b,e. However, the corresponding theoretical shear angles are $60^{\circ}$ and $30^{\circ}$, see dotted lines in Figure 5e. The discrepancy between the theoretical ${ }^{13}$ and experimental macroscopic shear angles can be explained by the fact that the former were calculated assuming inner and outer curvature radii equal to zero, while the ECAP die here used was designed with $\mathrm{R}=\mathrm{r}=8 \mathrm{~mm}$. Consequently shear does not take place along a single plane, but along a fan - like sheaf of planes. Finally, Figure $5 \mathrm{~d}$ shows that the direction of grain fragmentation makes $60^{\circ}$ with the pressing direction; this fragmentation is a general occurrence, which presumably takes place along the most active slip systems, that is, [111] and

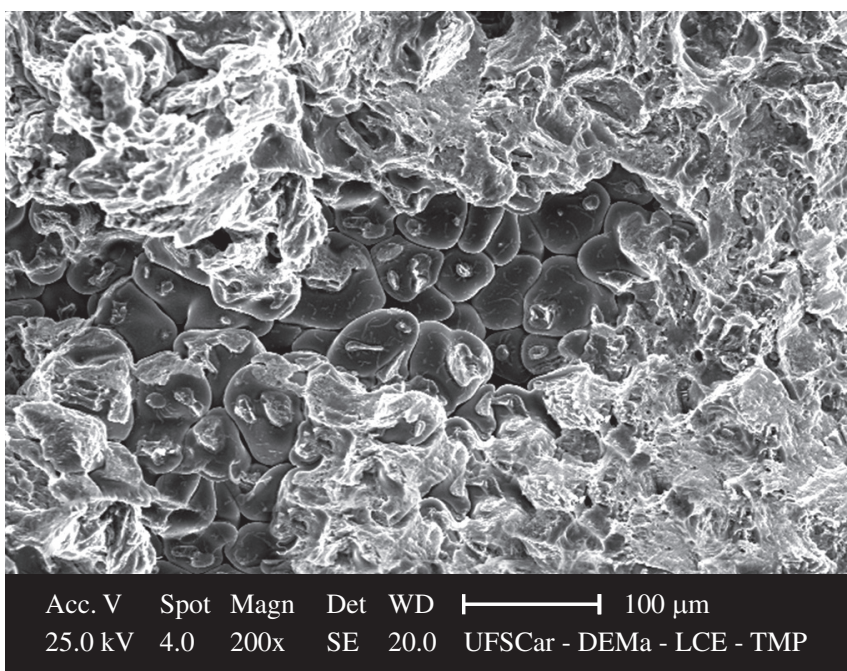

Figure 7. Scanning electron microscope fractography of the $0 \mathrm{X}$ (non deformed) tensile specime fracture surface showing a large shrinkage void.

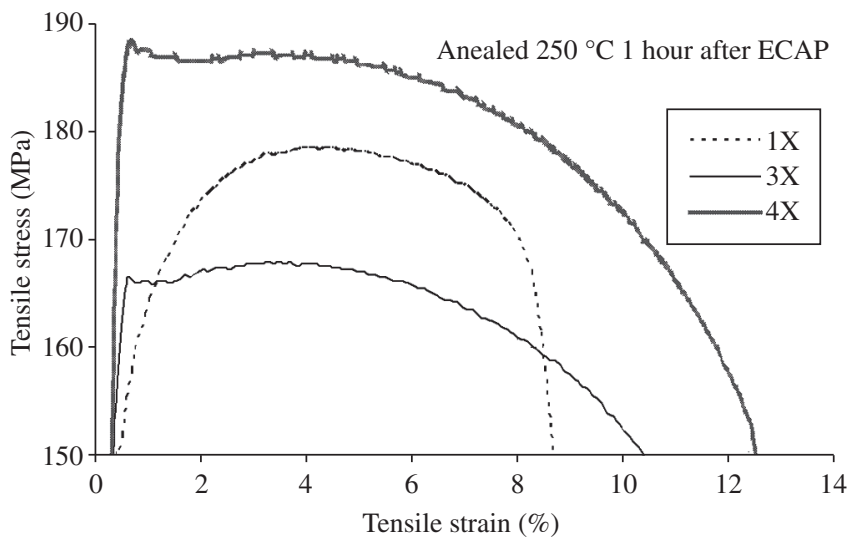

Figure 8. Engineering strain - stress curves of three post-deformation annealed specimens (enlargement of fig 2-a).

$<110>$. Said feature is related to the macroscopic grain orientation and in a previous paper ${ }^{20}$ a numerical description of the evolution of the grain axes orientation was developed, with results displaying a relatively good match with TEM observations by Wu et al. ${ }^{21}$. As for the fine microstructure, Figure 6 shows that the diffraction pattern of the $1 \mathrm{X}$ sample exhibits incomplete rings indicating low angle boundaries or, more precisely, sub-boundaries, whilst in the $4 \mathrm{X}$ sample the ring pattern is more continuous, meaning that the sub-boundaries have turned into high angle boundaries. In the introduction it has been mentioned that such evolution from low to high boundaries is supposed to be the main mechanism responsible for crystalline grain formation. The large particles shown in Figure $6 \mathrm{a}$ are $\mathrm{Al}_{2} \mathrm{Cu}$ precipitated during the slow cooling from the homogenizing temperature. In the $4 \mathrm{X}$ sample, non-equilibrium boundaries, probably formed by polygonized dislocation walls ${ }^{7}$ are indicated by the arrows; the non-equilibrium condition is also revealed by the strong diffraction contrast near the boundaries, an indication of elastic strain.

After annealing the deformed samples exhibit different microstructures, see Figure $6 \mathrm{c}, \mathrm{d}$ showing the 4XR specimen annealed at $250{ }^{\circ} \mathrm{C}$ and $300{ }^{\circ} \mathrm{C}$, respectively. In the former micrograph the main characteristics are the formation of equilibrium or near - equilibrium 
boundaries and a lower dislocation density. The nature of the grain boundaries is indicated by the presence of well defined extinction contours which, according to the dynamic theory of diffraction contrast are contours of similar grain depth in a thin foil; they appear in TEM images when some family of planes of the given grain is in the Bragg reflection condition. Additionally, the grains show straight sides, which is another characteristic of equilibrium boundaries. As for the $300{ }^{\circ} \mathrm{C}$ annealed material, see Figure $6 \mathrm{~d}$, the following features are relevant: i) accentuated coarsening of the $\mathrm{Al}_{2} \mathrm{Cu}$ precipitates; ii) the grain interiors appear to be totally free from dislocations; iii) complete recrystallization, and iv) discontinuous grain growth. That the $300{ }^{\circ} \mathrm{C}$ anneal is sufficient to fully recrystallize the $\mathrm{Al}-4 \% \mathrm{Cu}$ alloy is clearly shown by the hardness curve of Figure 9, obtained on a $4 \mathrm{X}$ sample, where softening begins at $250{ }^{\circ} \mathrm{C}$ and reaches the maximum value at $300{ }^{\circ} \mathrm{C} / 1$ hour.

Figure 10 shows micrographs of the $1 \mathrm{XR}$ and $4 \mathrm{XR}$ samples, which are characterized by a very different work hardening behaviour, see Figure 8; examination of the fine microstructure suggests that both grain size and nature of the grain or sub - grain boundaries play an important role in that phenomenon. Indeed, from measurements performed on a number of TEM micrographs, of which Figure 10 is a typical example, the grain size of the $1 \mathrm{XR}$ and $4 \mathrm{XR}$ samples was found to be close to 700 and $400 \mathrm{~nm}$, respectively. This means that dislocation absorption at the boundaries is easier in the latter since the defects mean free path is smaller, thus decreasing the likeli-

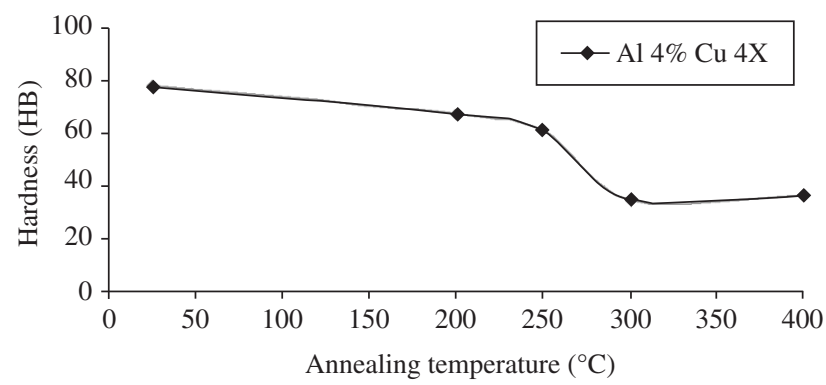

Figure 9. Hardness of sample 4x after annealing at 200, 250, 300 and 400 degrees Celsius.

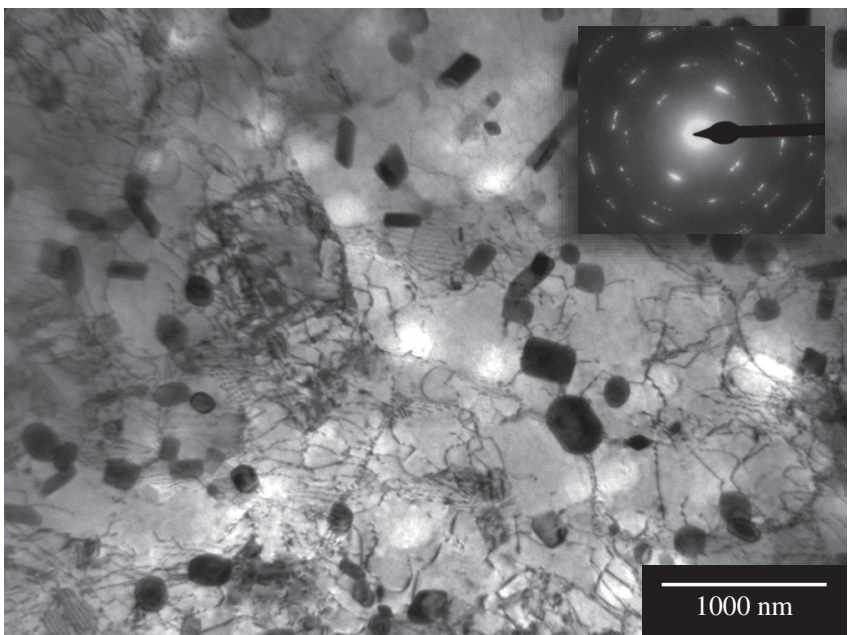

(a) hood of dislocation interaction. The second cause of lack of work hardening may be found in the grain boundary character, and from the diffraction patterns displayed in Figure 10, it is apparent that the proportion of high angle boundary is higher in the 4XR than in the 1XR sample. Recalling that the work hardening exponents of the aforementioned samples are 0.03 and 0.08 , respectively, it can be concluded that the dislocation absorption rate depends also of the grain boundary character, being faster for high angle boundaries. Although it was not possible to separate the effect of grain boundary character from that of grain size, the results confirm data from Sun and collaborators who studied two groups of commercially pure $\mathrm{Al}$ samples of similar grain size but differing in the proportion of high angle boundaries, and found that work hardening was much lower when these boundaries are predominant ${ }^{22}$. On the other hand, a more recent paper on two groups of severely deformed $\mathrm{Cu}$, exhibiting low and high angle boundaries showed the opposite trend ${ }^{23}$. However, the authors did not take into consideration that the groups also differed in grain size and dislocation density, having been produced by two different SPD techniques.

Returning to the strain hardening differences shown in Figure 8, it is possible to further speculate on their causes by recalling that after one ECAP pass, the sub-boundaries are ill-defined, have low capacity for dislocation storage and continue to be so after the anneal. Hence, the "effective" grains are still large and the material exhibits the conventional work hardening behaviour. Indeed, Figure 8 shows that the $1 \mathrm{XR}$ sample strength is due to that phenomenon. Instead, the stress - strain curves of the other two samples are completely flat and their strength can be attributed to the small grain size.

At any rate, the influence of grain boundary character on the mechanism of strain hardening is still not fully understood.

\section{Conclusions}

After only four ECAP passes, the tensile strength of an $\mathrm{Al}-4 \% \mathrm{Cu}$ alloy showed an increase of $300 \%$, not too distant from the $250 \%$ displayed by sample $2 \mathrm{X}$, meaning that grain size reduction is a fast process. Apparently, the elongation also increases but observation of the tensile specimens fracture surface suggests that the reference material, that is, the $0 \mathrm{X}$ sample had low ductility due to solidification defects. At any rate, the good combination strength - ductility resulted in very high values of static toughness, viz. $22 \mathrm{MJ} \mathrm{m}^{-2}$ displayed after four passes. Absence of work hardening was attributed

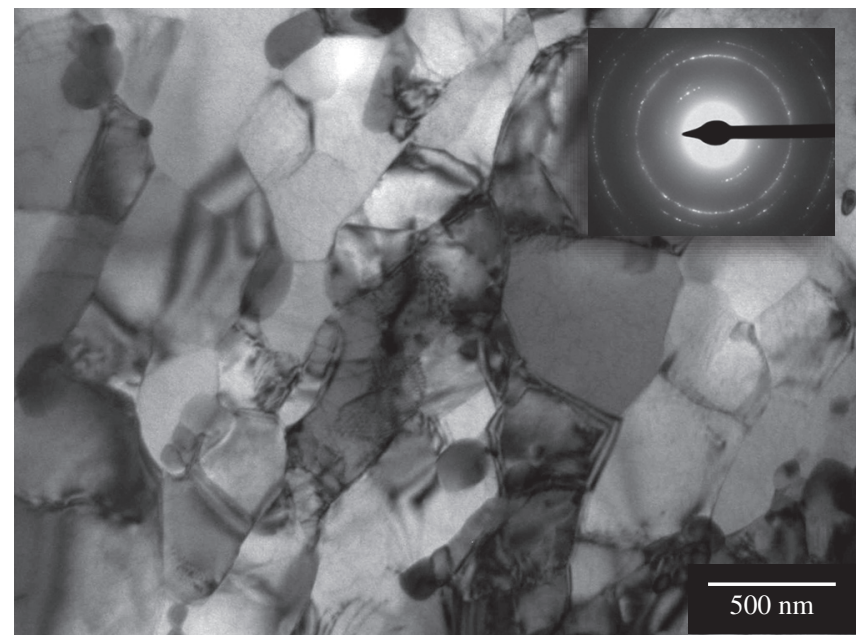

(b)

Figure 10. Transmission electron microscope and diffraction patterns of samples $1 \mathrm{XR}$ and $4 \mathrm{XR}$. 
to the small distance between grain or sub-grain boundaries and to the grain boundary character: the larger the grain boundary angle the easier the dislocations are absorbed, thus, the working hardening phenomenon is reduced.

In conclusion, the present work shows that deformation by ECAP is a very efficient method to achieve high strength and reasonable ductility and that evaluation of the latter property needs a complete characterization of the raw material to avoid false comparisons. Also, it was ascertained that after the second pass, ECAP deformation exerts a defect closure effect, thus "correcting" unsound raw material. Finally, the work hardening behavior has been described and a tentative discussion on the relevant causes has been attempted

\section{References}

1. Valiev RZ, Korznikov AV, Mulykov RR. Structure and properties of ultrafine-grained materials produced by severe plastic deformation. Materials Science Engineering A 1993; 168:141-148.

2. Segal VM. Materials processing by simple shear. Materials Science Engineering A 1995; 197:157-164.

3. Valiev RZ, Langdon TG. Principles of equal-channel angular pressing as a processing tool for grain refinement. Progress in Materials Science 2006; 51:881-981.

4. Liu Q, Hansen N. Macroscopic and microscopic subdivision of a cold rolled single crystal of cubic orientation. Proceedings of the Royal Society 1998; A454:2555-2591.

5. Bay B, Hansen N, Huges DA, Kuhlmann-Wilsdorf D. Overview no. 96 evolution of f.c.c. deformation structures in polyslip. Acta Metallurgica Materialia 1992; 40:205-219.

6. Xu C, Furukawa M, Horita Z, Langdon TG. Developing a model for grain refinement in equal-channel angular pressing. Materials Science Forum 2006; 503-504:19-24.

7. Iwahashi Y, Horita Z, Nemoto M, Langdon TG. The process of grain refinement in equal-channel angular pressing. Acta Materialia 1998; 46:3317-3331.

8. Chang CP, Sun PL, Kao PW. Deformation induced grain boundaries in commercially pure aluminium. Acta Materialia 2000; 48:3377-3385.

9. Meyer M, Mishra A, Benson DJ. Mechanical properties of nanocrystalline materials. Progress in Materials Science 2006; 51:427-556.

10. Valiev RZ, Alexandrov IV, Zhu YT, Lowe TC. Paradox of strength and ductility in metals processed by severe plastic deformation. Journal of Materials Research 2002; 17:5-8.
11. Iwahashi Y, Wang J, Horita Z, Nemoto M, Langdon TG. Principle of equal-channel angular pressing for the processing of ultra-fine grained materials. Scripta Materialia 1996; 35:143-146.

12. Fang DR, Zhang ZF, Wu SD, Huang CX, Zhang H, Zhao NQ, Li JJ. Effect of equal channel angular pressing on tensile properties and fracture modes of casting Al-Cu alloys. Materials Science Engineering 2006; A426:305-313

13. Furukawa M, Horita Z, Langdon TG. Factors influencing the shearing patterns in equal-channel angular pressing. Materials Science Engineering 2002; A332:97-109.

14. Gholinia A, Prangnell PB, Markushev MV. The effect of strain path on the development of deformation structures in severely deformed aluminium alloys processed by ECAE. Acta Materialia 2001; 48:1115-1130.

15. Zhu YT, Lowe TC. Observations and issues on mechanisms of grain refinement during ECAP process. Materials Science and Engineering 2000; A291:46-53.

16. Prados E, Sordi V, Ferrante M. (artigo a ser publicado). Materials Science Engineering (2008).

17. Park JH, Lee YS, Nam WJ, Park KT. Comparison of compressive deformation of ultra - fine grained $5083 \mathrm{Al}$ alloy at 77 and $298 \mathrm{~K}$. Metallurgical Transaction A 2005; 36A:1365-1368.

18. Wang YM, Ma E. Strain hardening, strain rate sensitivity, and ductility of nanostructured metals. Materials Science Engineering A 2004; 375-377:46-52

19. McFadden SX, Mishra RS, Valiev RZ, Zhilaev AP, Mukherjee AK. Low-temperature superplasticity in nanostructured nickel and metal alloys. Nature 1999; 398:684-686.

20. Signorelli JW, Turner PA, Sordi V, Ferrante M, Vieira EM, Bolmaro RE. Computational modeling of texture and microstructure evolution in $\mathrm{Al}$ alloys deformed by ECAE. Scripta Materialia 2006; 55:1099-1102.

21. Wu PC, Chang CP, Kao PW. The distribution of dislocation walls in the early processing stage of equal channel angular extrusion. Materials Science Engineering A 2004; 374:196-203.

22. Sun PL, Cerreta EK, Bingert JF, Gray(III) GT, Hundley MF. Enhanced tensile ductility through boundary structure engineering in ultrafine-grained aluminum. Materials Science Engineering A 2007; 464:343-350.

23. Zhao YH, Bingert JF, Zhu YT, Liao XZ, Valiev RZ, Horita Z, Langdon TG, Zhou YZ, Lavernia EJ. Tougher ultrafine grain $\mathrm{Cu}$ via high-angle grain boundaries and low dislocation density. Applied Physics Letters 2008; 92:081903-05. 